\title{
Hospitalisations from birth to 5 years in a population cohort of Western Australian children with intellectual disability
}

\author{
K Williams, H Leonard, E Tursan d'Espaignet, L Colvin, L Slack-Smith, F Stanley
}

Arch Dis Child 2005;90:1243-1248. doi: 10.1136/adc.2004.062422

See end of article for
authors' affiliations
$\ldots \ldots \ldots \ldots \ldots \ldots . . . . .$.
Correspondence to:
Dr H Leonard, Telethon
Institute for Child Health
Research, PO Box 855 ,
West Perth, WA, Australia
6872 ; hleonard@
ichr.uwa.edu.au
Accepted
22 December 2004

\begin{abstract}
Aims: To describe the hospitalisation history in the first five years of life for all children born in Western Australia (WA) between 1983 and 1992 and diagnosed with intellectual disability (ID).

Methods: Unit record linkage of the WA Midwives Collection, WA Intellectual Disability Database, and the WA Hospital Morbidity Dataset provided the population database of WA born children with and without ID. Affected children were divided into those co-affected with autism spectrum disorders (ASD), and those whose ID had or had no known biomedical cause. Those without a biomedical cause were further subdivided into mild-moderate and severe categories.

Results: On average, ID affected children were more likely than non-affected children to be admitted to hospital (RR: 1.64; $95 \% \mathrm{Cl} 1.6$ to 1.7), on more occasions (5.3 versus 2.2 admissions), for longer (29.6 versus 8.3 days), and for a larger range of clinical diagnoses. The only exception was the group of children co-diagnosed with ASD whose hospitalisation profile resembled more that of non-affected children.

Conclusions: This total population study is unique because of the availability of the system of linkable population registers and administrative health databases in WA. The results indicated that this vulnerable population of children with ID has substantial medical needs. This paper points to the need for authorities to develop supportive programmes for this population especially in the current climate of de-medicalisation of ID. More research is not only needed on the welfare of the affected children but also on the impact of the substantial medical and other needs of affected children on the rest of their immediate and extended families.
\end{abstract}

A lthough intellectual disability (ID) comprises about 7\% of all disabling conditions in Australia, ${ }^{1}$ relatively little is known about its causes and sequelae. A similar situation applies in other economically developed countries. In a recent blueprint for action aimed at improving the health of persons with ID (commonly referred to as mental retardation in the USA), the US Surgeon General recently argued that "the lack of population-based data on prevalence of mental retardation and the health status and service needs of this population impedes planning and allocating resources for their care". ${ }^{2}$ The blueprint specifically called for the need to collect data on the health status of persons with mental retardation in relation to the use, organisation, and financing of their health services.

This population based study aimed to describe hospital admissions for children with ID compared with non-affected children. It examined and compared the principal causes, frequency and duration of admissions for the first five years of life.

\section{METHODS}

Health researchers in Western Australia (WA) have access to a comprehensive system of population based datasets linkable at unit record level. ${ }^{3}$ Records on children with ID were linked to the WA Hospital Morbidity Database and the WA Midwives Collection to produce a population database of WA born children with and without ID.

The ID records were sourced from the WA Disability Services Commission (DSC), the major provider of disability services in the State, and from the WA Department of Education. Children identified through DSC were considered to have an ID if: (1) they had an intelligent quotient less than 70 on formal testing; (2) they had a condition known to be associated with ID (for example, Down's syndrome); or (3) they are clearly documented in their DSC records as having ID. The education sector defines children as ID affected "if they demonstrate significant deficits in adaptive behaviour and academic achievement and demonstrate intellectual functioning two or more SDs below the mean on an approved measure of cognitive functioning" ${ }^{4}$

The Heber version of the American Association on Mental Retardation (AAMR) classification system ${ }^{5}$ allows for the division of ID cases into those with and without ASD. ID cases were divided into those with ASD, those with a biomedical cause and the remainder into mild-moderate, severe, and unspecified categories.

Although ID is typically diagnosed before 5 years of age, some mild cases may not be identified until well into school age. Allowing for this lag, we feel that the information we have on the ID status of the cohort of infants born in WA from 1983 to 1992 inclusive, is now fairly complete. Our denominator for this study was children born in WA. We excluded infants who died in the first four weeks with the deaths being mostly from birth defects, and complications of low birth weight and prematurity. We have no information on children who left the State within the first five years of their life. We, however, estimated out-migration for the total WA population to be about $6 \%$ from 2001 Australian census unpublished data that we requested from the Australian Bureau of Statistics. At this stage, we have no reason to believe that the families of children with or who subsequently develop ID were more or less likely to move from WA. Our study base therefore included 241839 neonatal survivors, 3522 of whom were affected with ID (table 1).

Abbreviations: AAMR, American Association on Mental Retardation; ASD, autism spectrum disorders; DSC, Disability Services Commission; ID, intellectual disability; WA, Western Australia 
Table 1 Hospital admissions for first five years of life for neonatal survivors among cohort of children born in WA 1983-92 by ID status

\begin{tabular}{|c|c|c|c|c|c|c|c|}
\hline & \multicolumn{6}{|l|}{ Children with ID } & \multirow[b]{2}{*}{$\begin{array}{l}\text { All children } \\
\text { without ID }\end{array}$} \\
\hline & With ASD & $\begin{array}{l}\text { Medically } \\
\text { diagnosed }\end{array}$ & Severe & $\begin{array}{l}\text { Mild or } \\
\text { moderate }\end{array}$ & Unspecified & $\begin{array}{l}\text { All children } \\
\text { with ID }\end{array}$ & \\
\hline Total number of children & 191 & 604 & 223 & 2111 & 393 & 3522 & 238317 \\
\hline No. of children admitted to hospital & 124 & 569 & 192 & 1586 & 317 & 2788 & 114819 \\
\hline Proportion of children admitted (\%) & 64.9 & 94.2 & 86.1 & 75.1 & 80.7 & 79.2 & 48.2 \\
\hline No. of hospital admissions & 370 & 4348 & 1692 & 6836 & 1522 & 14768 & 253431 \\
\hline Mean no. of admissions per child (SD) & $1.9(3.3)^{* *}$ & $7.2(8.3)$ & $7.6(11.1)$ & $3.3(4.9)$ & $3.9(5.4)$ & $4.2(6.3)$ & $1.1(2.1)$ \\
\hline $\begin{array}{l}\text { Median no. of admissions per child } \\
\text { (interquartile range) }\end{array}$ & $1(0-3)$ & $5(2-8)$ & $4(1-10)$ & $2(1-4)$ & $2(1-5)$ & $2(1-5)$ & $0(0-1)$ \\
\hline $\begin{array}{l}\text { Mean no. of admissions } \\
\text { per child admitted (SD) }\end{array}$ & $3.0(3.7)^{*}$ & $7.6(8.3)^{\star *}$ & $8.8(11.5)^{\star *}$ & $4.3(5.0)^{* *}$ & $4.8(5.7)^{\star *}$ & $5.3(6.7)^{\star *}$ & $2.2(2.5)$ \\
\hline $\begin{array}{l}\text { Median no. of admissions } \\
\text { per child admitted (interquartile range) }\end{array}$ & $2(1-4)$ & $5(3-9)$ & $5(2-11)$ & $3(1-5)$ & $3(1-5)$ & $2(3-6)$ & $1(1-2)$ \\
\hline $\begin{array}{l}\text { Mean of total no. of days in } \\
\text { hospital per child admitted (SD) }\end{array}$ & $9.5(16.0) \mathrm{NS}$ & $45.3(63.4)^{* *}$ & $50.0(82.0)^{* *}$ & $23.4(49.3)^{\star *}$ & $30.5(54.2)^{* *}$ & $29.9(55.9)^{* *}$ & $8.3(18.6)$ \\
\hline $\begin{array}{l}\text { Median no. of days in hospital } \\
\text { per child admitted (interquartile range) }\end{array}$ & $4(1-10)$ & $21(8-54)$ & $20(6-59)$ & $8(3-22)$ & $9(3-27)$ & $10(3-30)$ & $3(1-8)$ \\
\hline
\end{tabular}

The interquartile range refers to data pertaining to the 25 th and 75 th centiles.

All statistical tests done row-wise against value for non-ID affected children. NS, not significant; ${ }^{*} \mathrm{p}<.05$; ${ }^{* *} \mathrm{p}<0.001$.

We have reported on all hospital admissions occurring in the first five years of life including those originating in the neonatal period but excluding those associated with normal birthing episodes. Morbidity data were viewed at both episode and at individual child level. The principal diagnosis, for each admission episode, was constructed from information available at time of hospital discharge and coded using the Australian amended version of the Ninth Revision of the International Classification of Diseases (ICD-9). ${ }^{6}$ Researchers had used these principal diagnoses to develop a list of 15 clinically relevant categories (see Appendix for list of codes) for a previous study into hospitalisation in WA children. ${ }^{78}$ To allow for comparisons with their broad findings, we used the same list of clinically relevant categories. Duration of stay was calculated based on admission and discharge dates. Duration was allocated 0.5 days where admission and discharge occurred on the same day.

We derived means (with their standard deviations) as well as medians (and their associated interquartile range-25th and 75 th centiles) to describe measures of central tendency in the data. Relative risks and their 95\% confidence intervals were used to test the relation between categorical variables; and Student's $t$ tests to assess differences in means. All analyses were conducted using Stata version $8 .{ }^{9}$

This project was approved by the Institute's institutional ethics committee (Princess Margaret Hospital Ethics Committee), and by the WA Health Department Confidentiality of Health Information Committee.

\section{RESULTS}

\section{Causes for admission to hospital}

Seventy nine per cent of children with ID had been admitted to hospital in their first five years compared with $48 \%$ of children without ID (table 1). These proportions yielded a relative risk of 1.64 (95\% CI 1.6 to $1.7, \mathrm{p}<0.001)$. The proportions admitted to hospital ranged from 65\% for children co-affected by ASD to $94 \%$ for those with a definite medical diagnosis. Compared with non-affected children these proportions yielded relative risks that ranged from 1.3 (95\% CI 1.2 to 1.5 ) for the children with ASD to 2.0 (95\% CI 1.9 to 2.0 ) for children with medically diagnosed ID (table 2).

As would be expected for children with ID, there were high relative risks of admission for morbidities associated with the central nervous system and mental conditions, and to a lesser extent with congenital anomalies. Although smaller in magnitude, the risks of hospitalisation for the other clinically relevant categories were also significantly higher for children with ID. The 124 children with ASD were the exception with a morbidity admission pattern more similar to those without ID.

\section{Frequency and duration of admission to hospital}

Children with ID had on average been admitted 4.2 times (SD 6.3 ) in the first five years of their life compared with 1.1 admissions (SD 2.1) for children not affected by ID $(p<0.001)$ (table 1$)$. With each admission lasting 3.8 days on average, each of the 114819 children without ID who was admitted would have spent on average 8.3 days (SD 8.6) in hospital by their fifth birthday (tables 1 and 4). In contrast, children with ID had significantly higher corresponding means for all ID categories combined. The mean number of admissions per child admitted ranged from 3.0 for ID children with ASD to 8.8 for children with severe ID (table 3). With the exception of children with ID and ASD, all children with ID had significantly longer hospital stays (per child admitted and per admission episode) compared with children without ID. The mean duration of hospitalisation for children admitted in the first five years of their life ranged from 9.5 days (SD 16.0) for ID children with ASD (not statistically different from non-ID children) to an average of 50.0 days (SD 82.0) for children with severe ID.

While $48 \%$ of unaffected children had a hospital admission, this applied to $94 \%$ of children with medically diagnosed ID (RR: $1.96,95 \%$ CI 1.9 to 2.0 ) and $65 \%$ of those children with ASD (RR: $1.4,95 \%$ CI 1.2 to 1.5 ). Only $12 \%$ of children without ID had been admitted three or more times compared with $47 \%$ for all children with ID (RR: $4.1,95 \%$ CI 3.9 to 4.2 ) (table 4). Even those with ASD recorded a level twice that for children without ID. Over the history of their admissions, only $6 \%$ of children without ID had been admitted for three or more clinically relevant categories (table 5). This compared with $34 \%$ of all children affected with ID (RR: 5.4, 95\% CI 5.2 to 5.7).

\section{DISCUSSION}

To our knowledge, this is the first report to describe the hospitalisation pattern in a total population of children with ID. This study has provided useful information on hospital admissions up to 5 years of age for children with ID compared with the general population. It also allowed comparison by type and severity of ID. This study focused on hospitalisations in the first five years of life, and thus for 

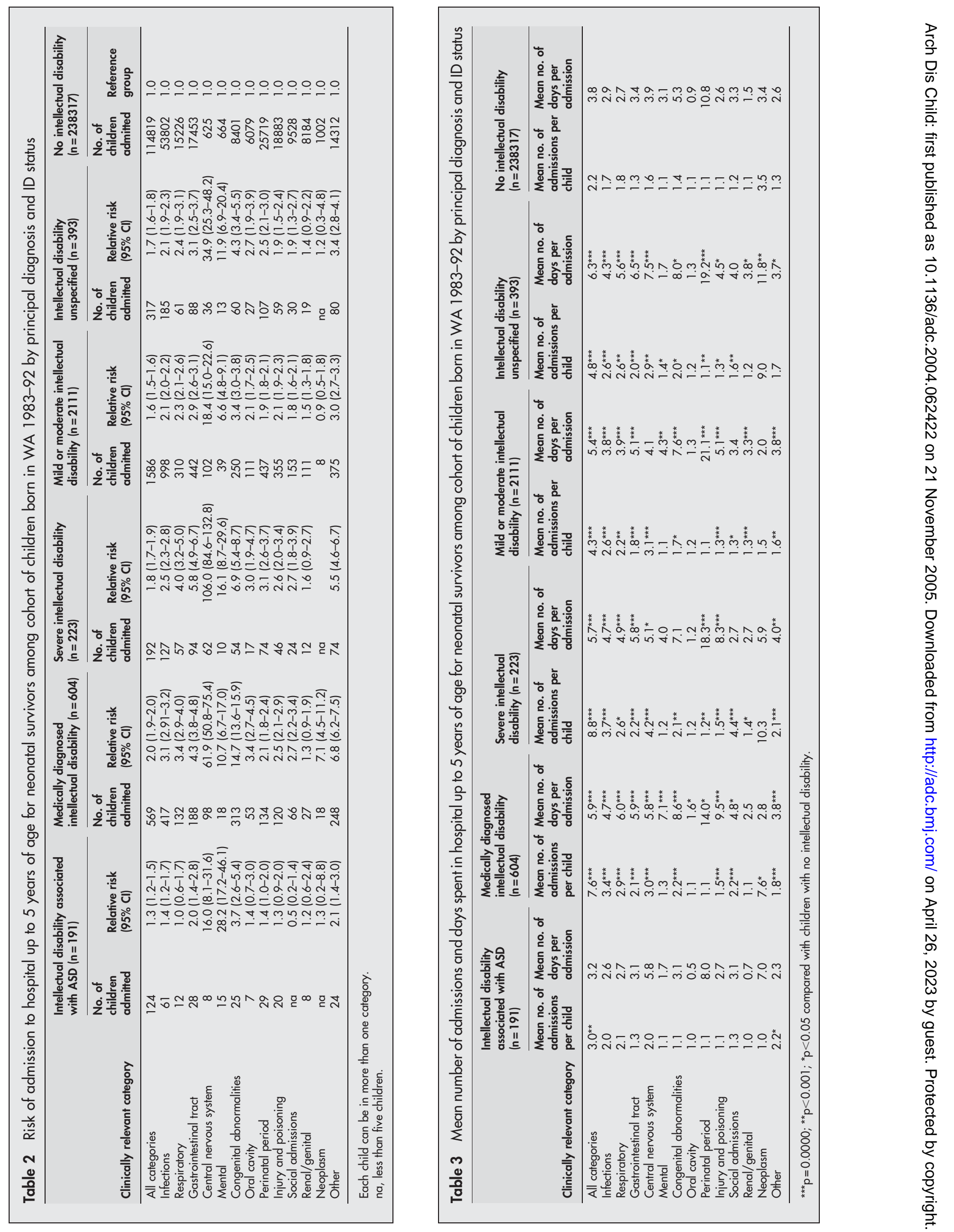
Table 4 Frequency of hospital admissions up to 5 years of age for neonatal survivors among cohort of children born in WA 1983-92 by ID status

\begin{tabular}{|c|c|c|c|c|c|c|c|c|c|c|c|c|}
\hline \multirow[b]{2}{*}{ No. of times admitted } & \multicolumn{2}{|c|}{$\begin{array}{l}\text { Intellectual } \\
\text { disability } \\
\text { associated with } \\
\text { ASD }\end{array}$} & \multicolumn{2}{|c|}{$\begin{array}{l}\text { Medically } \\
\text { diagnosed } \\
\text { intellectual } \\
\text { disability }\end{array}$} & \multicolumn{2}{|c|}{$\begin{array}{l}\text { Severe intellectual } \\
\text { disability }\end{array}$} & \multicolumn{2}{|c|}{$\begin{array}{l}\text { Mild or moderate } \\
\text { intellectual } \\
\text { disability }\end{array}$} & \multicolumn{2}{|c|}{$\begin{array}{l}\text { Intellectual } \\
\text { disability } \\
\text { unspecified }\end{array}$} & \multicolumn{2}{|c|}{$\begin{array}{l}\text { No intellectual } \\
\text { disability }\end{array}$} \\
\hline & $\begin{array}{l}\text { No. of } \\
\text { children }\end{array}$ & $\begin{array}{l}\% \text { of } \\
\text { cohort }\end{array}$ & $\begin{array}{l}\text { No. of } \\
\text { children }\end{array}$ & $\begin{array}{l}\% \text { of } \\
\text { cohort }\end{array}$ & $\begin{array}{l}\text { No. of } \\
\text { children }\end{array}$ & $\begin{array}{l}\% \text { of } \\
\text { cohort }\end{array}$ & $\begin{array}{l}\text { No. of } \\
\text { children }\end{array}$ & $\begin{array}{l}\% \text { of } \\
\text { cohort }\end{array}$ & $\begin{array}{l}\text { No. of } \\
\text { children }\end{array}$ & $\begin{array}{l}\% \text { of } \\
\text { cohort }\end{array}$ & $\begin{array}{l}\text { No. of } \\
\text { children }\end{array}$ & $\begin{array}{l}\% \text { of } \\
\text { cohort }\end{array}$ \\
\hline Never admitted & 67 & 35.1 & 35 & 5.8 & 31 & 13.9 & 525 & 24.9 & 76 & 19.3 & 123498 & 51.8 \\
\hline Admitted at least once & 124 & $64.9^{* *}$ & 569 & $94.2^{* *}$ & 192 & $86.1^{* *}$ & 1586 & $75.1^{\star *}$ & 317 & 80.7 & 114819 & 48.2 \\
\hline 1 & 48 & 25.1 & 58 & 9.6 & 29 & 13.0 & 461 & 21.8 & 82 & 20.9 & 61691 & 25.9 \\
\hline 2 & 27 & 14.1 & 61 & 10.1 & 22 & 9.9 & 279 & 13.2 & 63 & 16.0 & 25513 & 10.7 \\
\hline $3+$ & 49 & 25.7 & 450 & 74.5 & 141 & 63.2 & 846 & 40.1 & 172 & 43.8 & 27615 & 11.6 \\
\hline Total & 191 & 100.0 & 604 & 100.0 & 223 & 100.0 & 2111 & 100.0 & 393 & 100.0 & 238317 & 100.0 \\
\hline
\end{tabular}

children with ID was independent of the age at which ID was diagnosed. The results clearly show that children with ID were more likely to be admitted to hospital on more occasions and with a larger range of clinical diagnoses than nonaffected children. The only exception was in the group of cases co-diagnosed with ASD.

This study has only been possible because of the existence of a population based ID register in WA. The ID register is the only such one in Australia and other than those few US centres in Atlanta, Florida, ${ }^{10}{ }^{11}$ and California, ${ }^{12}$ it is one of the few places in the world with the capacity to carry out rigorous epidemiological ID research. A unique feature of our register is that it is capable of being linked at unit record level to a variety of other databases including the WA Midwives and Hospital Morbidity databases, ${ }^{3}$ as well as the WA Cerebral Palsy $^{13}$ and WA Birth Defects Registers, ${ }^{14}$ also maintained by our Institute. This infrastructure has the capacity to provide a window on all of childhood disability that also extends to include the investigation of the antecedents and co-morbidities.

What we have done in this study is to make an important start in measuring the health status of the ID population to allow for appropriate planning for health service needs. This is however very much a first step as this report only focuses on the hospital morbidity patterns for the first five years of life and does not consider later childhood or the adult population. There were a number of reasons for this. We used the previously identified cohort of WA children born between 1983 and $1992^{15}$ to ensure that ascertainment of ID was as complete as possible and that those children only being ascertained through educational sources would have had the opportunity to be identified. Thus, as we were limited in the number of years of hospitalisation history that would be available for the later births, we elected to restrict our analysis to the first five years of life.

Given what we have achieved in relation to the existing literature this is a landmark study. Because of the clear need to develop policy for the medical management of people with ID a review of international studies comparing the prevalence of health problems in people with and without ID was recently conducted. ${ }^{16}$ Only seven studies were identified meeting the criteria for research quality and of these only one could be considered population based. This was a Dutch study which, using a computerised general practice database to identify 318 people with ID and compare them with 48459 people without ID, found that those with ID had 2.5 times more health problems. ${ }^{17}$ None of the other studies, with samples of between 29 and 336 ID affected people, were population based. Although it is difficult to make an exact comparison between the health problems identified in general practice and our findings using hospitalisation data, there were some similarities. As might be expected some of their highest odds ratios were for categories such as congenital anomalies (OR 13.8, 95\% CI 8.2 to 23.4), epilepsy (OR 15.4, 95\% CI 10.7 to 22.2), premature/immature live born infant (OR 4.4, 95\% CI 2.5 to 7.8), other disorders CNS (OR $4.4,95 \%$ CI 2.6 to 7.7 ), and all perinatal morbidity (OR 3.4, $95 \%$ CI 2.0 to 5.7). However, we reported in our childhood population that although admission for central nervous system and mental conditions provided the higher relative risks for admission to hospital, the greatest burden in terms of the number of individual children hospitalised were for infections, conditions operating in the perinatal period, gastrointestinal and respiratory conditions, as well as injury

Table 5 Number of diagnostic categories experienced by children up to 5 years of age for neonatal survivors among cohort of children born in WA $1983-92$ by ID status

\begin{tabular}{|c|c|c|c|c|c|c|c|c|c|c|c|c|}
\hline \multirow[b]{2}{*}{$\begin{array}{l}\text { No. of diagnosis } \\
\text { categories at admission }\end{array}$} & \multicolumn{2}{|c|}{$\begin{array}{l}\text { Intellectual } \\
\text { disability associated } \\
\text { with ASD }\end{array}$} & \multicolumn{2}{|c|}{$\begin{array}{l}\text { Medically } \\
\text { diagnosed } \\
\text { intellectual } \\
\text { disability }\end{array}$} & \multicolumn{2}{|c|}{$\begin{array}{l}\text { Severe intellectual } \\
\text { disability }\end{array}$} & \multicolumn{2}{|c|}{$\begin{array}{l}\text { Mild or moderate } \\
\text { intellectual } \\
\text { disability }\end{array}$} & \multicolumn{2}{|c|}{$\begin{array}{l}\text { Intellectual } \\
\text { disability } \\
\text { unspecified }\end{array}$} & \multicolumn{2}{|c|}{$\begin{array}{l}\text { No intellectual } \\
\text { disability }\end{array}$} \\
\hline & $\begin{array}{l}\text { No. of } \\
\text { children }\end{array}$ & $\begin{array}{l}\% \text { of } \\
\text { cohort }\end{array}$ & $\begin{array}{l}\text { No. of } \\
\text { children }\end{array}$ & $\begin{array}{l}\text { \% of } \\
\text { cohort }\end{array}$ & $\begin{array}{l}\text { No. of } \\
\text { children }\end{array}$ & $\begin{array}{l}\% \text { of } \\
\text { cohort }\end{array}$ & $\begin{array}{l}\text { No. of } \\
\text { children }\end{array}$ & $\begin{array}{l}\% \text { of } \\
\text { cohort }\end{array}$ & $\begin{array}{l}\text { No. of } \\
\text { children }\end{array}$ & $\begin{array}{l}\% \text { of } \\
\text { cohort }\end{array}$ & $\begin{array}{l}\text { No. of } \\
\text { children }\end{array}$ & $\begin{array}{l}\% \text { of } \\
\text { cohort }\end{array}$ \\
\hline Never admitted & 67 & 35.1 & 35 & 5.8 & 31 & 13.9 & 525 & 24.9 & 76 & 19.3 & 123498 & 51.8 \\
\hline Admitted at least once & 124 & $64.9^{* *}$ & 569 & $94.2^{* *}$ & 192 & $86.1^{\text {** }}$ & 1586 & $75.1^{\text {** }}$ & 317 & $80.7^{* *}$ & 114819 & 48.2 \\
\hline 1 & 60 & 31.4 & 87 & 14.4 & 36 & 16.1 & 591 & 28.0 & 114 & 29.0 & 71842 & 30.1 \\
\hline 2 & 31 & 16.2 & 128 & 21.2 & 33 & 14.8 & 422 & 20.0 & 88 & 22.4 & 28083 & 11.8 \\
\hline 3 & 19 & 9.9 & 134 & 22.2 & 44 & 19.7 & 258 & 12.2 & 50 & 12.7 & 9933 & 4.2 \\
\hline $4+$ & 14 & 7.3 & 220 & 36.4 & 79 & 35.4 & 315 & 14.9 & 65 & 16.5 & 4961 & 2.1 \\
\hline Total & 191 & 100.0 & 604 & 100.0 & 223 & 100.0 & 2111 & 100.0 & 393 & 100.0 & 238317 & 100.0 \\
\hline
\end{tabular}

${ }^{*} \mathrm{p}<0.05 ;{ }^{* *} \mathrm{p}<0.001$ comparing ID affected children admitted at least once with children free of intellectual disability and never admitted to hospital. 


\section{What is already known on this topic}

- Very little is known on a population basis about the health status and hospitalisation patterns of children with intellectual disability

- The lack of such data is impeding progress in planning health services and allocation of resources to this population
What this study adds

- It provides for the first time information on hospitalisation patterns for a total population of children with intellectual disability in the first five years of their lives

- We have been able to show how the patterns vary by category of intellectual disability and by the clinical category of the hospitalisation. and poisoning. A weakness of the Dutch study is that it does not provide an age breakdown of the populations although it is stated that $20 \%$ of those with ID and $30 \%$ of the remainder were over 50 years. Thus one would surmise that it is a predominantly adult population.

In their review, Jansen and colleagues ${ }^{16}$ commented on the methodological weaknesses of many of the seven studies such as the absence both of a case definition for people with ID and information about ID level. They also mentioned that method of recruitment influences representativeness of the sample and the issue of bias if consent is required where those who do consent may be different from those who do not. The major benefits of our study design include having a clear case definition, information on type and severity of ID, population based ascertainment (and thus no consent related bias), and no data acquisition burden on medical practitioners as our information is obtained by record linkage.

In general we found that the risks of hospitalisation were increased for all children with ID except for those with ASD. The behavioural characteristics of children with ASD may make it more difficult for their parents to engage them within the health system or, as often has been our clinical perception, they may be physically healthier than other children with ID. The risks of hospitalisations were higher for those with severe and medically related ID and a little lower for those with mild-moderate and unspecified ID. Children with Down's syndrome comprise a substantial proportion $(40 \%)$ of those with a medical diagnosis. In a questionnaire study we previously described the co-morbidities of these children and their use of health services from a parental perspective. ${ }^{15}$ During the previous year just over a third were reported to have had a hospital admission-commonly for dental procedures, ear surgery, eye problems, and respiratory problems. The methods we have developed and followed here would now allow us to separate out and examine the hospital experience of children with Down's syndrome or in other specific ID categories. Our results are also consistent with some other recent Australian research. A study of young Australians (aged 5-29 years) with ID reported a rate of injury hospitalisations twice that for the general population. ${ }^{18}$ Another study reported the median length of stay for a child with trisomy 21 (without congenital heart disease) with common respiratory conditions was 2-3 times greater than in patients without trisomy $21 .^{19}$

In conclusion, we believe these results have substantial relevance and implications for policy at an international level. There has been, in the current climate of de-medicalisation of ID, a universal trend away from the provision of specific clinical services for these children. The results presented in this paper clearly show that children with ID have substantial medical needs that culminate in higher risk of hospitalisation for a variety of clinical diagnoses in the first five years of their life. The impact of these admissions most likely not only impact on the welfare of the affected children but also on the rest of their immediate and extended families. Moreover there is concern that as more and more people with ID are deinstitutionalised there is not the necessary primary care infrastructure to provide for their medical care. ${ }^{16}$ This is an often hidden population ${ }^{20}$ in which we have shown at least in early childhood to have high medical needs.

This preliminary report is thus an important first step to understanding the health status and medical needs of this vulnerable population. These medical needs may not necessarily decline as these children progress into adulthood. Our next priority will be to extend the analysis over a larger birth cohort to provide more statistical power and to use more sophisticated techniques to allow for examination of patterns of hospital morbidity throughout childhood. We also see a need to supplement this quantitative research with qualitative work to document the associated personal, social, and economic costs to ensure evidence based policy and programme decisions for affected children and their families.

\section{ACKNOWLEDGEMENTS}

We acknowledge the Telethon Institute for Child Health Research, Department of Education and Training, Catholic Education Office, Association of Independent Schools Western Australia, and the Birth Defects Registry for assistance with data collection and other aspects of the study including organisational support. We would also like particularly to thank Harry Bouckley, Kate Rowell, Elvira Edwards, Jane Pavledis, Mairead McCoy, Tessa Vincent, Maureen Thomson, Audrey Jackson, Peter Cosgrove, and Huan Ngyuen. We would also like to acknowledge the special contribution provided by Jenny Bourke. This work was funded by the National Health and Medical Research Council (Program Grant \# 003209).

\section{Authors' affiliations}

K Williams, Visiting Researcher, Centre for Child Health Research, University of Western Australia; and WA Department of Health,

Australia

H Leonard, E Tursan d'Espaignet, L Colvin, F Stanley, Centre for Child Health Research, University of Western Australia, Telethon Institute for Child Health Research, Australia

L Slack-Smith, School of Population Health and School of Dentistry, The University of Western Australia, Australia

Competing interests: none declared

\section{APPENDIX}

See table Al for a list of ICD-9 codes used for the various clinically relevant categories.

\section{REFERENCES}

1 Australian Institute of Health and Welfare. Australia's health 2002. Canberra: AlHW, 2002

2 US Public Health Service. Closing the gap: a national blueprint to improve the health of individuals with mental retardation. Report of the Surgeon General's Conference on Health Disparities and Mental Retardation. Washington, DC: US Department of Health and Human Services, 2001.

3 Stanley FJ, Read AW, Kurinczuk JJ, et al. A population maternal and child health research database for research and policy evaluation in Western Australia. Semin Neonatol 1997;2:195-201.

4 Education Department of Western Australia. Social justice in education: policy and guidelines for the education of students with disability. Perth: Education Department of Western Australia, 1995.

5 Heber R. A manual on terminology and classification in mental retardation. Am J Ment Defic 1961;64. 
Table Al List of ICD-9 codes used for the various clinically relevant categories

\begin{tabular}{|c|c|}
\hline Clinically relevant categories & ICD-9-CM codes \\
\hline Infections & $\begin{array}{l}001-139 ; 320-326 ; 372.0 ; 373.4-373.5 ; 376.0-376.1 ; 380.1 ; 381.0-381.5 ; 382 ; 383.0-383.3 ; 383.9 ; \\
390-398 ; 420-422 ; 460-466 ; 473-475 ; 480-490 ; 494 ; 510 ; 511.0-511.1 ; 523.3 ; 540 ; 580 ; 590 ; 595 ; \\
599.0 ; 604 ; 614 ; 616.0-616.4 ; 646.6 ; 658.4 ; 675 ; 680-699 ; 711 ; 730 ; 780.3 ; 780.6 ; \text { V04.8; V12.0; } \\
\text { V18.8; V75 (exclude 090) }\end{array}$ \\
\hline Respiratory & $\begin{array}{l}470-472 ; 476-478 ; 491-493 ; 495-508 ; 511.8-519.9 ; 786 ; \mathrm{V} 17.5-\mathrm{V} 17.6 ; \mathrm{V} 42.6 ; \mathrm{V} 71.2 \text { (exclude 516.9; } \\
786.6 \text { ) }\end{array}$ \\
\hline Gastrointestinal tract & 530-578; 783; 787; 789; 793.4; V12.7; V18.5; V55.0-V55.4 (exclude 540) \\
\hline Central nervous system & 331-359.9 (exclude 335.0; 359.0-359.3) \\
\hline Mental & 290-319; V11; V17.0; V18.4; V40; V62.8-V62.9; V66.3; V67.3; V71.0; V79 \\
\hline Congenital anomalies & $\begin{array}{l}090 ; 228.0-228.1 ; 243 ; 255.2 ; 270.0-271.3 ; 272.6-272.7 ; 275.1-275.4 ; 276.3 ; 277.0-277.2 ; 277.5 ; \\
282 ; 286 ; 288.2 ; 330 ; 335.0 ; 359.0-359.3 ; 362.7 ; 371.5 ; 389.1 ; 457.8 ; 524.0 ; 579.0 ; 579.8-579.9 ; \\
593.0 ; 593.7 ; 648.5 ; 654.0 ; 654.6-654.8 ; 740-759.9 ; 762.8 ; 771.0-771.2 ; 776.5 ; 778.0 ; 778.6 ; V 13.6 ; \\
\text { V19.5; V82.4 }\end{array}$ \\
\hline Oral cavity & 520-529; V41.6; V53.4; V58.5; V72.2 (exclude 523.3; 524.0) \\
\hline Perinatal period & 760-779; V13.7 (exclude 762.8; 771.0-771.2; 776.5; 778.0; 778.6) \\
\hline Injury and poisoning & 800-999; V15.5-V15.6; V66.4; V67.4; V71.3-V71.6; V82.5 \\
\hline Social admissions & V20; V60-V65, (exclude V62.8-V62.9) \\
\hline Renal/genital & $\begin{array}{l}\text { 250.4; 581-589; 591-629; 646.2; 788; 791; 793.5; 794.4; V18.6-V18.7; V43.5; V50.2; V53.6; V55.6; } \\
\text { V56.0-V56.8; V59.4 (exclude 593.0; 593.4; 593.7; 595; 599.0; 604; 614; 616.0-616.4) }\end{array}$ \\
\hline Neoplasms & 140-239; V10; V16; V58.0-V58.1; V66.1-V66.2; V67.1-V67.2; V71.1; V76 (exclude 228.0-228.1) \\
\hline $\begin{array}{l}\text { Pregnancy/newborn and birth admission (all } \\
\text { excluded) }\end{array}$ & 630-676; V22-V29; V30-V39; (exclude 646.2; 646.6; 648.5; 654.0; 654.6-654.8; 675) \\
\hline All other & All other codes not included above \\
\hline
\end{tabular}

6 National Coding Centre. The Australian Version of the International Classification of Diseases, 9th Revision, clinical modification (ICD-9-CM). Sydney: University of Sydney, 1996

7 Silva D, Palandri G, Bower C, et al. Child and adolescent health in Western Australia-an overview. Perth: Health Department of Western Australia and TVW Telethon Institute for Child Health Research, 1999.

8 Colvin L. Childhood hospital morbidity profiles for children born with birth defects in Western Australia, 1980-1995 [MPH]. Perth: University of Western Australia, 2000

9 StataCorp. Stata Statistical Software: release 8.0. College Station, TX: Stata Corporation, 2003.

10 Blair C, Scott KG. Proportion of LD placements associated with low socioeconomic status: evidence for a gradient? J Special Educ 2002;36:14-22.

11 Chapman DA, Scott KG, Mason CA. Early risk factors for mental retardation role of maternal age and maternal education. Am J Ment Retard 2002; 107:46-59.

12 Croen LA, Grether JK, Selvin S. The epidemiology of mental retardation of unknown cause. Pediatrics 2001;107(6):e86
13 Watson L, Stanley FJ, Blair E. Report of the Western Australian Cerebral Palsy Register to Birth Year 1994. Perth: Telethon Institute for Child Health Research, 1999.

14 Bower $\mathrm{C}$. The value of a birth defects register: the Western Australian experience. Perspect Hum Biol 1995; 1:29-36.

15 Leonard H, Petterson B, Bower C, et al. Prevalence of intellectual disability in Western Australia. Paediatr Perinat Epidemiol 2003;17:58-67.

16 Jansen DE, Krol B, Groothoff JW, et al. People with intellectual disability and their health problems: a review of comparative studies. J Intellect Disabil Res 2004;48:93-102.

17 van Schrojenstein Lantman-De Valk HM, Metsemakers JF, Haveman MJ, et al. Health problems in people with intellectual disability in general practice: a comparative study. Fam Pract 2000;17:405-7.

18 Sherrard J, Tonge B, Ozanne-Smith J. Injury in young people with intellectual disability: descriptive epidemiology. Ini Prev 2001;7:56-61.

19 Hilton J, Fitzgerald D, Cooper D. Respiratory morbidity of hospitalized children with trisomy 21. J Paediatr Child Health 1999;35:383-6.

20 Beange HP. Caring for a vulnerable population. Med J Aust 1996; 164:159-60. 